\title{
Modelisation of the different alteration factor of durum wheat stored in Tunisia
}

\author{
Bouslah Fatima $^{1}$, Khaled Elmoueddeb ${ }^{1}$, Mohamed Elyes Hamza ${ }^{2}$ \\ ${ }^{1}$ Department of Mecanical Engineering High School of Engineer University of Jendouba, 9070, Medjez El Bab, Tunisia \\ ${ }^{2}$ Department of Agricultural Engineering Forestry water, National Agronomic Institute of Tunisia, University of \\ Carthage 1082 Cité Mahrajène Le Belvédère Tuni, Tunisia
}

How to cite this paper: Fatima, B., Elmoueddeb, K., Hamza M. E. (2020) Modelisation of the different alteration factor of durum wheat stored in Tunisia. International Journal of Food Science and Agriculture, 4(1), 12-17.

DOI: $10.26855 /$ ijfsa.2020.03.003

*Corresponding author: Bouslah Fatima, Department of Mecanical Engineering High School of Engineer University of Jendouba, 9070, Medjez El Bab, Tunisia.

\begin{abstract}
According to the analysis of the means, at the end of 6 months of storage of the two silos, the impurity levels is $0.94 \%$ for the control silo while it is $0.49 \%$ for the experimental silo. The rate of broken kernels increased during the storage period in the experimental silo and this reflects the effect of grain transfer from $0.41 \%$ to $0.48 \%$, while the attacked kernels decreased by $0.9 \%$ at $0.41 \%$. There was a higher incidence of dead insects in the control silo as this cell was retreated during filling and some live insects died by shaking the durum wheat from the experimental silo during removed grains. The models of the determined regression equations of the different durum degradation variables make it possible to note that moisture and temperature are the main triggers for the increase of losses by the damage to broken grains, attacked grains, mitered grains and dust, the proliferation of insects. This is validated by the models equations, which explain that each variable causes the other three in the presence of temperature and humidity. The increase of the attacked grains generates an elevation of the broken grains later all this will generate an increase of dust thanks to the activity of the insects. The presence of broken grains, dust, attacked and macerated grains at the beginning of durum storage in the experimental and control silos. All the models are explained inter alia by the attacked grains variable, which explains that this one is the main provocateur of the stored durum wheat alterations. Indicating that mitered grains (starchy grains) is one of the main factors in the commercial decommissioning of durum wheat. The dust results from all these degradation. Models of regression equations for the occurrence of live and dead insects show that these insect variables vary with storage time (days), moisture and temperature of model stored durum wheat. In addition to the regression equations of living and dead insects that are explained by the attacked, lean, harmful grains and other durum wheat grains stored model show that these latter factors facilitate the proliferation of insects in the durum wheat mass in the presence of temperature and humidity. The grains of other grains and pests are very fragile to be attacked by insects. The proliferation of insects weakens the conservation of durum wheat grains. Impurities are the residues of all the degradation of durum and other grains of other cereals. The variable impurity increases with the attacked grains, taking into account that the impurities evolve well with the temperature and humidity. It is noted that lean beans contribute to the degradation of durum wheat grains and show dust in the presence of temperature and humidity. Finally, the presence of broken grains, attacked, dust and impurities at the beginning of storage can inform us about the quality and quantity of durum grain losses at the end of the storage period.
\end{abstract}




\section{Keywords}

Cereals, wheat quality, loss of storage grain, Tunisia

\section{Introduction}

In Tunisia, cereal production does not cover the country's consumption needs. On average, we import $40 \%$ of our cereal requirements. In addition, the seasonal nature of cereal production requires us to store cereals for longer or shorter periods. Cereals are the most important source of food in Tunisia Energy intake for human consumption is higher than for all other foods combined. The identification of the losses through an experimental study, as well as the time of appearance of qualitative losses of durum wheat, during the period of storage in control and experimental cells could show that during 06 months. The roblems related to the storage of cereals and more particularly those posed by pests require effective solutions for the safeguarding of our cereal harvest and consequently of our basic food. The development of storage and conservation systems in Tunisia allows us to manage our long time ,grain stocks with the minimum of expenses.

Storage systems operate under a wide range of variables including climate, harvest type, humidity content end use of the product.

\section{Methodology}

To Identify through an analysis of the different types of losses, their causes and methods of determining these losses through a bibliographic study, Evaluate wheat quality (imported and local) at the experimental silo on receipt and delivery Determine the causes of quantity and quality losses (transportation, handling and storage) To inventory the various elements involved in the deterioration of the quality of wheat during the storage more or less prolonged. Propose a solution to reduce the different types of qualitative and quantitative losses wheat.

Three concrete cells of about 500 tons each for a period of 6 months

\section{Control cell}

Quantitative analysis and quality assessment were performed at the end of the storage period to be compared with results obtained at the experimental cell level.

\section{Experimental cell}

Every two months, The contents of the experimental cell are poured into another cell (bin transfer) stored after cleaning and disinfection and intended for experimentation.

\section{bin transfer cell}

Samples were taken after each technical operation.

The search for impurities is the operation, which aims at separating, classifying and weighing the various impurities contained in a sample. Different operations are necessary for the investigation of impurities after sieving. This operation carried out with great rigor while respecting the following conditions. Stirring time of 30 to 45 seconds, screen position, the sieving is by a movement or slots being oriented in the direction of movement.

The sieves used for the detection of impurities are of two types; the $2 \mathrm{~mm}$ slot screen and the $1 \mathrm{~mm}$ slot screen.

\section{$2 \mathrm{~mm}$ sieve}

grains of other cereals, heated grains, grains attacked by predators, grain midge, broken grain, sprouted grains and various impurities, separate impurities sprouted grains, broken grains.

\section{$1 \mathrm{~mm}$ sieve}

place the whole sieve in the cup of impurities proper for counting the number of insects in the overall sample Weigh the contents of each dish to $0.01 \mathrm{~g}$ and calculate the percentage of each category in relation to the mass of the sample.

\section{Results and Discussions}

The establishment of statistical interactions that link storage duration, humidity, grain temperature on the one hand 
and the different grains variables (broken, sprouted, heated attack, impurities, dust, scalds, other cereals, live and dead insects) and others predicts the importance of the different types of qualitative losses during the period of storage of cereals according to the experimental data. Regression analysis of different variables for durum and soft wheat was performed by XLSTAT 2015.

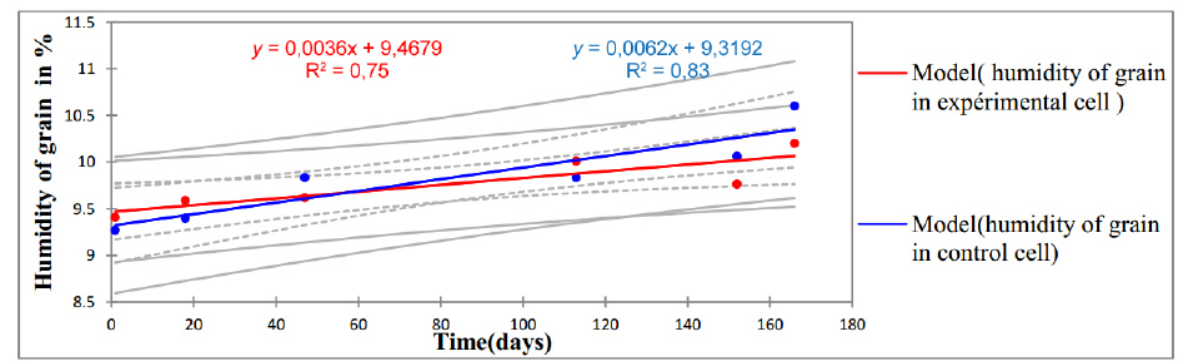

Fig 1. Regression of durum wheat grains humidity according to storage days

The trend of the grain humidity variable as a function of storage time shows that the slope of this linear regression is increasing with a regression coefficient $\mathrm{R}^{2}=75 \%$ for the experimental silo and $\mathrm{R}^{2}=83 \%$ for the control silo. This indicates that the models are representative and that the variation in grain humidity content of durum wheat is substantially increasing during the storage period. The transilage operation in the experimental silo limits the increase in the moisture content of the durum wheat. stored durum wheat (Figure 1).

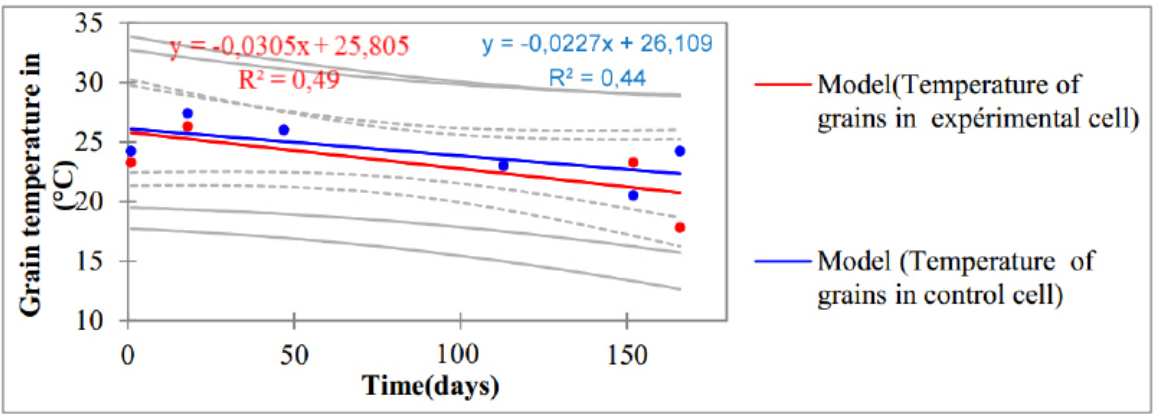

Fig 2. Regression of durum wheat grain temperature according to storage days

The trend of the temperature variable of the grains as a function of the storage time shows that the slope of this linear regression decreases with a regression coefficient $\mathrm{R}^{2}=0.49$ for the experimental silo and $\mathrm{R}^{2}=0.44$ for the control silo, the change in durum wheat grain temperature is decreasing during the storage period as the outside temperature decreases (June to December) (Figure 2).

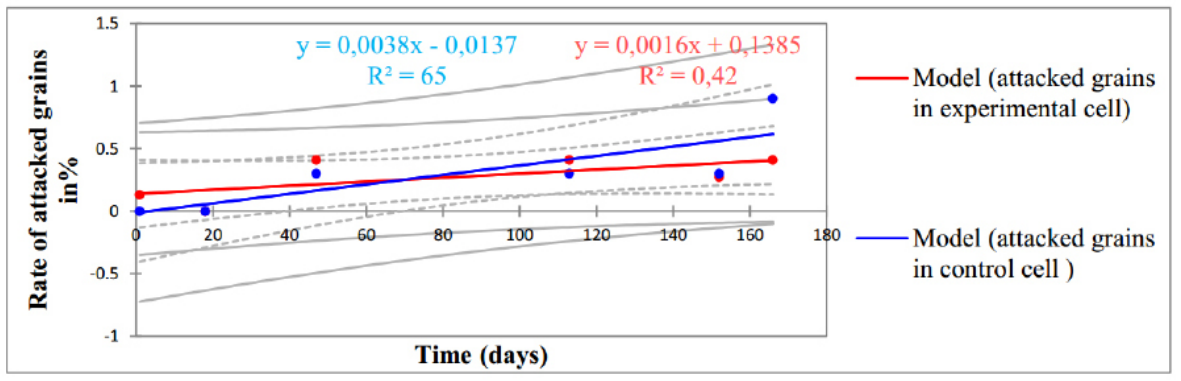

Fig3. Regression of the attacked durum grains according to storage days

The trend of the attacked durum wheat variable as a function of storage time shows that the slope of this linear regression is increasing with a regression coefficient $\mathrm{R}^{2}=65 \%$ for the control silo with a much larger slope. While the regression coefficient $\mathrm{R}^{2}=42 \%$ for the experimental silo with a slope, which explains and that the variation of the attacked grain rate of durum wheat in the control silo is greater than that of the experimental silo. The lack of aeration of durum wheat grains in the control silo increasingly favors their attack during the storage period (Figure 3). 


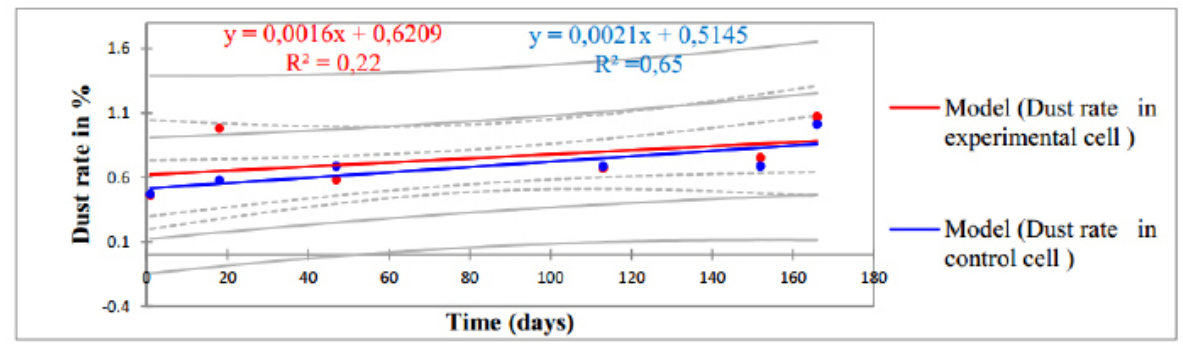

Fig 4. Regression of dust durum wheat grains according to storage days

The tendency of the dust variable as a function of the storage time shows that the slope of this linear regression is very small with a regression coefficient $\mathrm{R}^{2}=22 \%$ for the experimental silo is $\mathrm{R}^{2}=65 \%$ for the control silo. This explains why the dust variation in the durum wheat stock is more sustained as a function of time for the control silo (Figure 4).

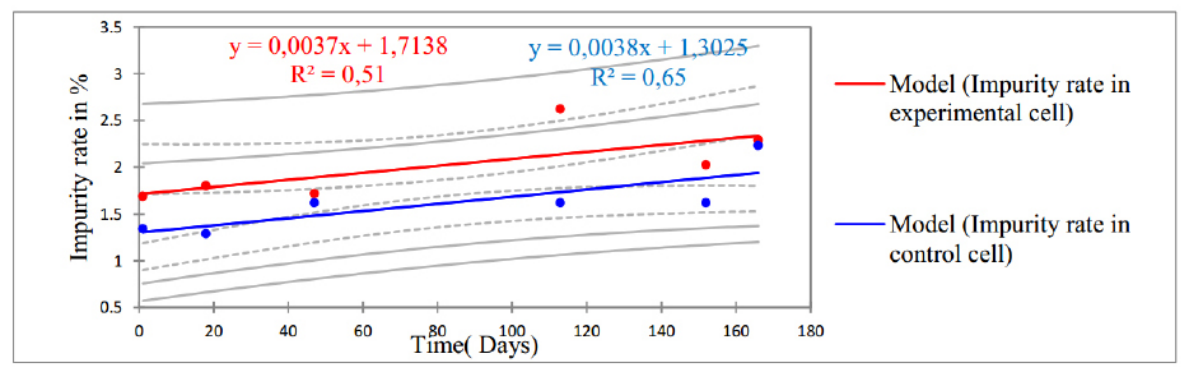

Fig 5. Regression of impurity in durum wheat grains according to storage days

The trend of the impurity variable of durum wheat grains as a function of storage time shows that the slope of this linear regression is increasing with a regression coefficient $\left(\mathrm{R}^{2}=0.51\right)$ for the experimental silo and $\left(\mathrm{R}^{2}=0,65\right)$ for the control silo. It is noted that the variation in the durum grain impurity rate is of equal importance in the two control and experimental silos during the storage period with regressions having almost the same slope (Figure 5).

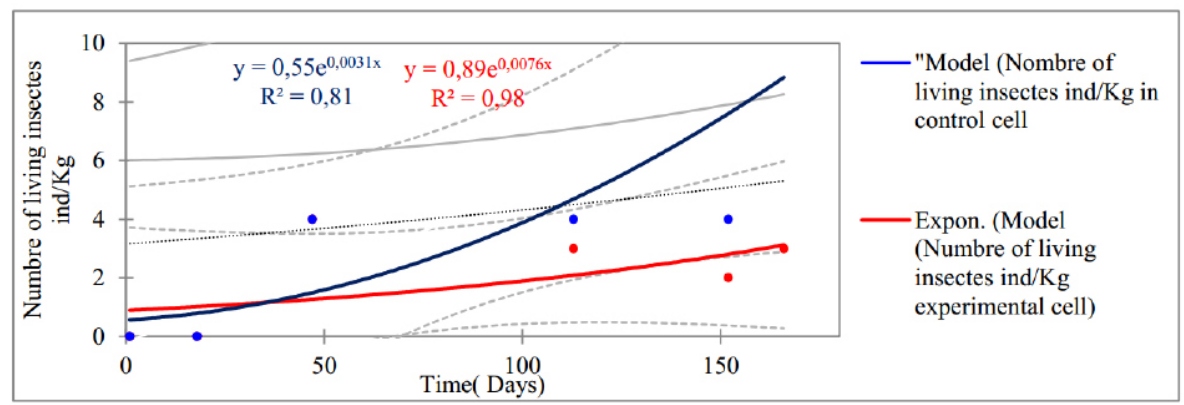

Fig 6. Regression of the evolution of living insects of durum wheat grains according to days of storage

The trend of the live insect variable as a function of storage time shows that the slope of this exponential regression with a regression coefficient $\mathrm{R}^{2}=81 \%$ for the control silo and $\mathrm{R}^{2}=98 \%$ for the experimental silo. The variation in the level of live insects in the durum wheat control silo is greater. In the control silo there is no transilage operation so it is an enclosed environment favorable for the increase in live insect levels of durum wheat (Figure 6).

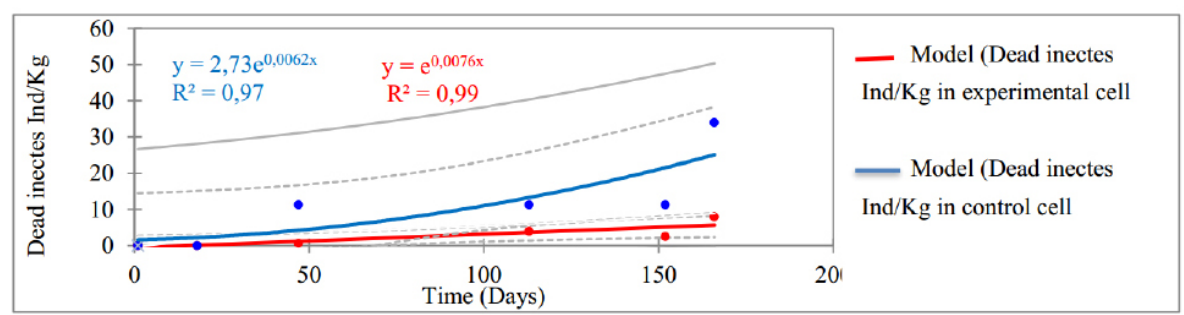

Fig 7. Regression of the evolution of dead insects of durum wheat grains according to the days of storage 
The trend of the dead insect variable as a function of storage time shows that the slope of this exponential regression is imploring with a regression coefficient $\mathrm{R}^{2}=97 \%$ for the control silo and $\mathrm{R}^{2}=99 \%$ for the experimental silo. This explains that this variation in the rate of dead insects is very remarkable during the durum wheat storage period in the control silo than the experimental silo. This appearance is related to the transilage of durum wheat grains from the experimental silo, which allows some aeration and under the shock effect of the grains as a result the cycle of multiplication of insects in the experimental silo is interrupted, which limits the number of dead insects (Figure 7).

humidity of grain, $\mathrm{Tg}$ : tempetur of grain, $\mathrm{j}$ : days, $\mathrm{G}$ ca: broken grains, $\mathrm{G}$ at: attacked grains, $\mathrm{G}$ au Ce: grains other cereals, In V: alive insects In M: dead insects, Pou: dust G mit: mitadin grains, G mai lean grains, Gnui: harmful grains,

$$
\begin{aligned}
& \mathrm{G} \text { ca }=6,2339+0,1306 * \mathrm{G} \text { at }-0,3453 * \text { Pou }-0,1239 * \mathrm{G} \text { mit } \quad\left(\mathrm{R}^{2}=0,99\right) \\
& \mathrm{G} \text { at }=-47,729+2,644 * \mathrm{Pou}+0,949 * \mathrm{G} \text { mit }+7,656 * \mathrm{G} \text { ca } \quad\left(\mathrm{R}^{2}=0,99\right) \\
& \text { Pou }=18,050-0,3590 * \mathrm{G} \text { mit }-2,895 * \mathrm{G} \mathrm{ca}+0,378 * \mathrm{G} \text { at } \quad\left(\mathrm{R}^{2}=0,99\right) \\
& \operatorname{Imp}=-27,489-0,002 * \mathrm{j}+2,760 * \mathrm{Hug}+0,112 * \operatorname{Tg} 0,87 \quad\left(\mathrm{R}^{2}=0,87\right) \\
& \mathrm{Imp}=-9,988+1,891 * \mathrm{G} \text { b T }-6,6143 * \mathrm{G} \text { au Ce }+0,586 * \mathrm{G} \text { at } \quad\left(\mathrm{R}^{2}=0,99\right) \\
& \text { In } \mathrm{V}=2,583-1,341 * \mathrm{G} \text { mai }-27,189 * \mathrm{G} \text { nui }+5,941 * \mathrm{G} \text { at } \quad\left(\mathrm{R}^{2}=0,99\right) \\
& \text { In. } \mathrm{M}=34,5252+0,0222 * \mathrm{j}-1,79257 * \mathrm{Hug}-0,6669 * \mathrm{Tg} \quad\left(\mathrm{R}^{2}=0,99\right) \\
& \text { In } \mathrm{M}=21,4392-0,886 * \mathrm{Tg}+3,5976 * \mathrm{GauCe}-0,7987 * \mathrm{G} \text { at } \quad\left(\mathrm{R}^{2}=0,99\right) \\
& \mathrm{G} \text { mit }=-104,555-0,007 * \mathrm{j}+10,096 * \mathrm{Hug}+1,039 * \mathrm{Tg} \quad\left(\mathrm{R}^{2}=0,96\right) \\
& \text { Gmit }=50,279-8,065 * \mathrm{G} \text { ca }+1,053 * \mathrm{G} \text { at }-2,785 * \text { Pou } \quad\left(\mathrm{R}^{2}=0,99\right)
\end{aligned}
$$

The models of the determined regression equations of the different durum degradation variables make it possible to note that humidity and temperature are the main factors for the increase of losses by the damage of broken grains, attacked grains, mitred grains and dust. This is validated by the equations $(1,2,3,4,5,6,7,8,9,10)$, which explain that each variable causes the other three in the presence of temperature and humidity. The increase of the attacked grains generates an elevation of the broken grains later all this will generate an increase of dust caused by the activity of the insects with presence of broken grains and dust, attacked and mitadin grains at the beginning of durum storage in the experimental and control silos. All the models are explained inter alia by the attacked grains variable, which explains that this one is the main problem of the stored durum wheat alterations. Indicating that mitadin grains (starchy or starchy grains) are one of the main factors in the commercial decommissioning of durum wheat. While the dust results from all these degradations. Models of regression equations for the occurrence of live and dead insects show that these insect variables vary with storage time (days), humidity and temperature of model stored durum wheat grains. In addition to the regression equations of living and dead insects that are explained by the attacked, lean, harmful grains and other durum wheat grains stored, show that these latter factors increase the proliferation of insects in the durum wheat mass in the presence of temperature and humidity.

\section{Conclusions}

The presence of broken grain and impurities are an important elements favorable to development insects. For this purpose, brand new lot must be properly cleaned before placing in stock. New knowledge on the overall evolution of the stored durum wheat ecosystem from this systemic approach should be useful for improving modern strategies for the integrated protection of stored cereals, for health quality management when stored for a long time.

\section{Acknowledgment}

This work is the resutat of the efforts of several researchers mainly Professor Errezgui Salah.

\section{References}

[1] Les problèmes de qualité du blé dur après stockage en Tunisie [Durum Wheat Storage Problems Quality in Tunisia]; International Journal of Innovation and Scientific Research, Fatima Bouslah, Khaled El Moueddeb, Mohamed Elyes Hamza; 2016, ISSN 2351-8014 Vol. 21No. 1 Mar. 2016, pp. 190-200 @ 2015 Innovative Space of Scientific Research Journals. 13p 
[2] Les problèmes de qualité du blé tendre après stockage dans les conditions climatiques chaudes (cas de la Tunisie); Fatima Bouslah; Khaled El Moueddeb; Mohamed Elyes Hamza; Ben Ncir Ahmed; 2016, Xth International Congress on Renewable Energy and the Environment; 23- 25 March 2016, Tunisia

[3] Étude des différents types de pertes de stockage et conservation des céréales dans les régions à climat chaud, Fatima Bouslah; Mohamed Elyes Hamza; Khaled El Moueddeb; 2017; Cet ouvrage a été composé par Edilivre 175, boulevard Anatole France -93200 Saint- Denis; France; 44p

[4] Compared Storage Quality Durum and Soft Wheat in Tunisia; Fatima Bouslah, Khaled El Moueddeb, Mohamed Elyes Hamza; 2017 14th Tunisia-Japan Symposium on Science, Society and Technology (TJASSST 2017); 24-26 Novembre 2017, Tunisia 